$\Phi=-1$

\title{
Dietary knowledge, attitude, and practice regarding prevention of iron deficiency anemia among pregnant women in Riyadh, Saudi Arabia
}

\author{
Ashwaq Ayidh Alosaimi ${ }^{1}$, Sabreen Abdullah Alamri ${ }^{2}$, Manal Mohammed \\ Abduljawad ${ }^{2}$, Sahar Mohammed Yakout ${ }^{3,4, *}$, Salma Abdelatty Moawed ${ }^{5}$ \\ ${ }^{1}$ Nurse, General Directorate of Health Affairs, Riyadh, Saudi Arabia \\ ${ }^{2}$ Nurse Specialist, Maternity and Children Hospital, Jeddah, Saudi Arabia \\ ${ }^{3}$ Assistant Professor, Maternity and Gynecologic Nursing, Alexandria University, Alexandria, Egypt \\ ${ }^{4}$ Assistant Professor, Maternity and Gynecologic Nursing, King Saud University, Riyadh, Saudi Arabia \\ ${ }^{5}$ Professor, Maternity and Gynecologic Nursing, Alexandria University, Alexandria, Egypt \\ Corresponding Author: Sahar M. Yakout \\ *Corresponding author E-mail: szamzam@ksu.edu.sa
}

\begin{abstract}
Background: Iron deficiency anemia (IDA) is recognized as the world's most widespread nutritional disorder, affecting 1.6 billion people that constitute about $25 \%$ of the global population, and it is one of the most common diseases complicating antenatal women worldwide, particularly in the developing countries. There have been few research studies on IDA in pregnancy in Arab countries including Saudi Arabia.

Objectives: This study aimed to assess the knowledge, attitude, and practice (KAP) on IDA among pregnant women in Riyadh, Saudi Arabia.

Methods: A correlational study was used to collect data from a convenience sample of 314 pregnant women in Al Yammamah Hospital. Socio-demographic and obstetric characteristics, knowledge, attitude, and practice toward IDA during pregnancy questionnaire were determined and were analyzed for association. The KAP questionnaire was developed by the researchers based on Food and Agriculture Organization (FAO) guidelines.

Results: Majority of the participants were in the age group 31 years and older who were university graduates, housewives, and have a monthly income of more than 5000 Saudi Riyals. In addition to their obstetric history, majorities were multigravida and multipara, in their third trimester, had no previous surgical or obstetric surgical history or complications in their previous pregnancies. Significant associations were found between the level of hemoglobin and income and dietary practices. Education is a major predictor of knowledge, attitude and practice among Saudi pregnant women.

Conclusions: Saudi pregnant women have modest knowledge and positive attitude regarding IDA during pregnancy. Appropriate nutritional counseling during antenatal follow up should be encouraged and should include all women in reproductive age.
\end{abstract}

Keywords: Knowledge; Attitudes; Practice; Iron Deficiency Anemia; Pregnant Women.

\section{Introduction}

Iron deficiency anemia (IDA) is recognized as the world's most widespread nutritional disorder, affecting 1.6 billion people that constitute about $25 \%$ of the global population, and it is one of the most common disorders complicating antenatal women worldwide, particularly in the developing countries (Foote et al. 2013). This condition affects red blood cells and consequently their oxygen-carrying capacity is insufficient to meet all the body's physiologic needs, which may vary according to person's age, gender, altitude, smoking status, and different stages of pregnancy (Estadella et al. 2018). More so, this condition is thought to be the most common cause of anemia globally, but some other nutritional deficiencies (including folate, vitamin B12 and vitamin A), acute and chronic inflammation, parasitic infections, and inherited or acquired disorders can cause anemia as well (Lokeshwar et al. 2011).

Anemia can lead to some complications and risks for the pregnant women and the fetus that include increased risk of premature delivery, low birth weight babies, inadequate iron stores in the newborn, and increased risk of morbidity and mortality in perinatal and neonatal period and among pregnant females (Nivedita \& Shanthini 2016).

There have been few research studies on the epidemiology of IDA in pregnancy in Arab countries. The prevalence rate of this disorder usually ranges from $25 \%$ to $40 \%$. It appears that almost one-third of pregnant women in several Arab countries suffer from anemia. In Egypt 30\% of pregnant women are affected, 31\% in Iraq, 32\% in Morocco, 28\% in Qatar, 29\% in Tunisia, and 26\% in United Arab Emirates (World Health Organization 2011). The prevalence rate of IDA in Saudi Arabia exceeded its neighboring MENA countries (40\%) (World Health Organization 2011). This present research will provide a baseline data to further develop effective strategies and

Copyright $\odot$ Ashwaq A. Alosaimi et al. This is an open access article distributed under the Creative Commons Attribution License, which permits unrestricted use, distribution, and reproduction in any medium, provided the original work is properly cited. 
create increase awareness regarding the disorder among the pregnant women. The aim of this study was to assess the pregnant women knowledge, attitudes and practice toward IDA during pregnancy in Riyadh City, Saudi Arabia.

\subsection{Theoretical framework}

The current study is grounded on the Trans-Theoretical Model (TTM) of Behavioral Change developed by Horwath (1999). The TTM explains the process of how people attempt to modify health-risk behaviors to avoid health problems. It is successfully applied to a variety of health behavior areas, including smoking cessation, weight control, dietary change, exercise acquisition, and stress management. Within this model, there are sets of common principles that explain why people succeed and fail in changing their behavior (Fox \& Kilvert 2003).

\section{Methods}

\subsection{Design}

This present study employed a cross-sectional study. This design was used because it fits with the aim of the study and provides better understanding of the topic being investigated.

\subsection{Setting}

The data were collected from the antenatal care units affiliated to Al Yammamah Hospital in Riyadh, Saudi Arabia. The hospital contains 300 beds with antenatal outpatient services that provide free access to any healthcare services to a large group of pregnant women daily.

\subsection{Sample size}

The inclusion criteria were pregnant and willing to participate in the study. The exclusion criteria included non-Saudi, pregnant women with comorbid diseases, and women with complicated pregnancy. The sample size was calculated using the Sample Size Calculator of Creative Research Systems Software using a confidence level of 95\%, confidence interval of 4, and $800-1000$ women visiting the anti natal clinic in the setting of data collection monthly. The estimated sample size was calculated as 343 participants. Due to time constrain of the researchers, data recruitment was stopped after reaching 314 participants.

\subsection{Tools for data collection}

The study used a researcher-made survey tool that includes the following parts: demographics characteristics, obstetric profile, including nutritional practice during pregnancy, knowledge regarding anemia, and attitude toward anemia during pregnancy. The survey was developed by the investigators after reviewing the related literatures that share similar objectives. Questionnaire consisted of two parts: 1) the socio demographic profile and 2) the KAP questionnaire, which was adopted from the standardized KAP on IDA from Food and Agriculture Organization (FAO) guidelines (Macias \& Glasauer 2014). It included following variables: knowledge, attitude, practices; assessed through various relevant questions in each section. Response options for the nutritional practice during pregnancy were yes and no and responses options for knowledge were (2) yes, (1) no and (0) don't know. The total score for knowledge ranged from 0 to 32, the higher the score the higher the level of knowledge. Scores of $\leq 10$ was considered as poor, scores from 11 to 21 was considered as fair, and scores of 22 -32 was considered as good level of knowledge. Attitude scale included 8 items with 3-point Likert scale (3) Agree, (2) neutral and (1) don't agree. Total score for attitude ranged from 1 to 24 with higher scores reflected positive attitude and lower score reflected negative attitude toward anemia during pregnancy. The survey was tested for face and content validity through a review of 2 experts in maternity nursing who are holding a $\mathrm{PhD}$. It was translated into Arabic and piloted on 10 women and modified accordingly. The survey took 15 to 20 minutes to complete and the researchers were available to clarify any concerns. For illiterate women, the researchers conducted a separate interview for them. The survey was also tested for reliability before the main data analysis and the knowledge questionnaire reported a Cronbac's alpha of .69 and .71.

\subsection{Procedure of data collection}

The proposal of the study was approved by the Institutional Review Board at King Saud University and a permission to conduct the study was obtained from the authorized personnel at the local setting of data collection. The researchers communicated with the antenatal clinic manager about the time and process of data collection. The researchers visited the setting 3 times per week from 9.00am to 12.00am, March 2019. Women were approached by the researchers and the purposes of the study were explained and those who agreed to participate were asked to provide a consent.

\subsection{Ethical considerations}

In this study, all responses were treated with anonymity and confidentiality. This study used numerical coding to protect participant's identity. Participants received information containing their rights, including their right for voluntary participation and their right to withdraw at any time from the study without compromising patient care. There were no benefits or risks for participation in the study.

\subsection{Statistical analysis}

Descriptive statistics such as number and percentages were used to explain explanatory variables. Pearson product moment correlation was used to find the association between demographic and obstetric variables and women's knowledge and attitude toward anemia during pregnancy. All p-values $\leq 0.05$ was considered significant. All data were analyzed using SPSS version 21. 


\section{Results}

\subsection{Demographic characteristics of the study sample}

Majority (57.3\%) of the study participants belong to age group 31 years and older, while $42.3 \%$ were in the age group 21 to 30 years old. Regarding women's' education, $49 \%$ were university graduates, $17.2 \%$ had secondary school level, $22.9 \%$ reported intermediate level of education, and $9.8 \%$ were illiterate. Majority (97.8\%) of the women were housewives. As for the income, majority (93.3\%) reported that their income is more than 5000 Saudi riyals. Results of demographic characteristics of the study sample are presented in Table 1.

Table 1: Demographic Characteristics of the Study Sample

\begin{tabular}{|c|c|c|}
\hline Demographic items & $\mathrm{n}=314$ & $\%$ \\
\hline \multicolumn{3}{|l|}{ Age } \\
\hline$<20$ years old & 1 & 0.3 \\
\hline 21 to 30 years old & 133 & 42.3 \\
\hline$>31$ years old & 180 & 57.3 \\
\hline \multicolumn{3}{|l|}{ Education } \\
\hline Illiterate & 31 & 9.8 \\
\hline Intermediate & 72 & 22.9 \\
\hline Secondary & 54 & 17.2 \\
\hline University & 154 & 49 \\
\hline Others & 3 & 0.9 \\
\hline \multicolumn{3}{|l|}{ Occupation } \\
\hline Working & 7 & 2.2 \\
\hline House wife & 307 & 97.8 \\
\hline \multicolumn{3}{|l|}{ Income } \\
\hline Less than 5000 SR & 21 & 6.6 \\
\hline More than 5000SR & 293 & 93.3 \\
\hline
\end{tabular}

\subsection{Women's obstetric history}

Regarding the women's obstetric history, $96.2 \%$ of the participants reported that this was not their first pregnancy. Regarding gestational age, $54 \%$ were in the third trimester, $40 \%$ were in the second trimester and $6 \%$ were in the first trimester of pregnancy. Gravidness was reported as more than 4 times among 35\%, 4 times among 19.1\%, 3 times among 31.8\%, 2 times among 9.9\% and first time among 4.1\%. As for parity, $42 \%$ delivered more than 3 deliveries, 30.3\% delivered 3 times, 20\% delivered twice and 7.6\% once. Majority $(89.5 \%)$ reported having no complications during their pregnancies/deliveries/after delivery. Majority (92.6\%) of the study participants experienced vomiting and pica (88.8\%) during pregnancy. In addition, $78.3 \%$ reported that they had a one-year period between their current pregnancy and the previous one, $20.4 \%$ had more than one-year period apart from their pregnancies. Regarding medical history, majority $(93 \%)$ reported having no chronic problems, only 3.5\% reported having either hypertension or diabetes millets. As for surgical history, $92 \%$ said that they did not have any surgical procedures in the past. Similarly, $91 \%$ had no obstetric surgeries before while $9 \%$ gone through some obstetric procedures with no complications reported. Results of the participants' obstetric history are showed in Table 2 .

Table 2: Obstetric History of the Study Sample

\begin{tabular}{|c|c|c|}
\hline Items & $\mathrm{n}=314$ & $\%$ \\
\hline \multicolumn{3}{|l|}{ First pregnancy } \\
\hline Yes & 12 & 3.8 \\
\hline No & 302 & 96.2 \\
\hline \multicolumn{3}{|l|}{ Gestational age } \\
\hline $1^{\text {st }}$ trimester & 20 & 6 \\
\hline $2^{\text {nd }}$ trimester & 125 & 40 \\
\hline $3^{\text {rd }}$ trimester & 169 & 54 \\
\hline \multicolumn{3}{|l|}{ Gravidness } \\
\hline More than 4 times & 110 & 35 \\
\hline 4 times & 60 & 19.1 \\
\hline 3 times & 100 & 31.8 \\
\hline Twice & 31 & 9.9 \\
\hline Once & 13 & 4.1 . \\
\hline \multicolumn{3}{|l|}{ Parity } \\
\hline More than 3 times & 132 & 42 \\
\hline 3 times & 95 & 30.3 \\
\hline Twice & 63 & 20 \\
\hline Once & 24 & 7.6 \\
\hline \multicolumn{3}{|c|}{ Complication during previous pregnancy/delivery/after delivery } \\
\hline Yes & & 10.5 \\
\hline No & $\begin{array}{l}33 \\
281\end{array}$ & 89.5 \\
\hline \multicolumn{3}{|l|}{ Vomiting } \\
\hline Yes & 291 & 92.6 \\
\hline No & 23 & 7.4 \\
\hline \multicolumn{3}{|l|}{ Experience pica } \\
\hline Yes & 279 & 88.8 \\
\hline No & 35 & 11.2 \\
\hline \multicolumn{3}{|c|}{ Periods between pregnancies } \\
\hline More than 1 year & 64 & 20.4 \\
\hline One year & 246 & 78.3 \\
\hline Less than one year & 4 & 1.3 \\
\hline
\end{tabular}




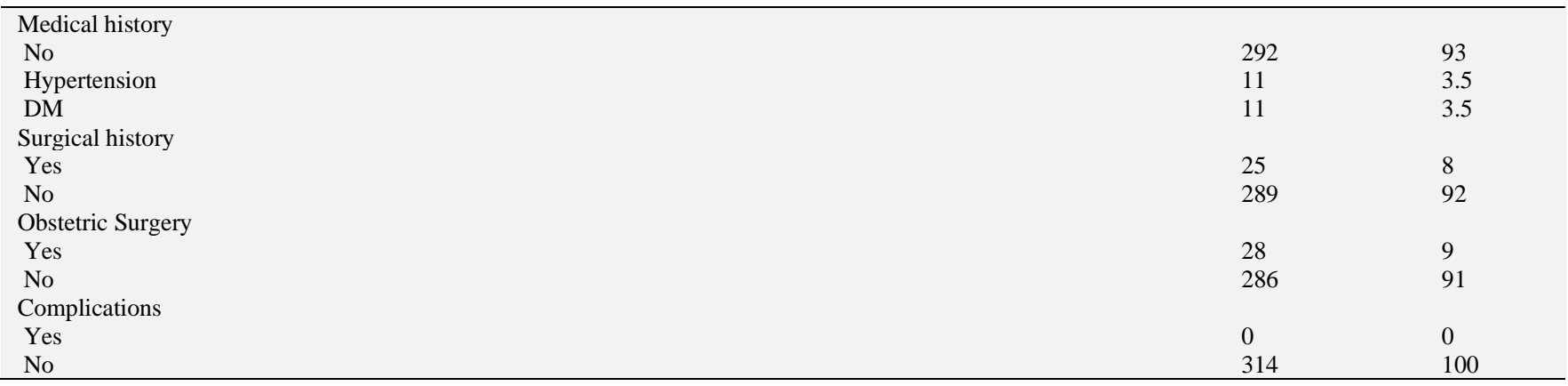

\subsection{Pregnant women nutritional practice during pregnancy}

Regarding women's nutritional habits during pregnancy, 99\% reported that they changed their nutrition habits, consuming enough fruits and leafy vegetables during pregnancy. Majority (83.4\%) showed that they consume enough protein during their pregnancy. Majority $(93 \%)$ of the women indicated that they skip meals sometimes. Most of the study participants $(64 \%)$ reported drinking tea or coffee during pregnancy while $36 \%$ reported otherwise. Among those who drink tea, 25\% drinks up to 4 cups a day, $19 \%$ reported 3 cups a day, $27 \% 2$ cups a day and $29 \%$ one cup a day. While those who drink coffee, $21 \%$ drink up to 4 cups a day, $25 \%$ reported having 3 cups a day, $32 \% 2$ cups a day and $22 \%$ one cup a day. Almost all participants $(97.18 \%)$ indicated that they received iron prescription during pregnancy and majority (78.98\%) received iron for more than 2 months. In addition, almost all the participants (99.7\%) reported having normal hemoglobin level during their pregnancy. Results of women's nutritional habits during pregnancy are presented in Table 3.

Table 3: Study Participant's Nutritional Practice during Pregnancy

\begin{tabular}{|c|c|c|}
\hline Items & $\mathrm{n}=314$ & $\%$ \\
\hline \multicolumn{3}{|c|}{ Change of nutritional habits } \\
\hline Yes & 311 & 99 \\
\hline No & 3 & 1 \\
\hline \multicolumn{3}{|l|}{ Consume enough fruits } \\
\hline Yes & 311 & 99 \\
\hline No & 3 & $1 \%$ \\
\hline \multicolumn{3}{|c|}{ Consume enough leafy vegetables } \\
\hline Yes & 311 & 99 \\
\hline No & 3 & 1 \\
\hline \multicolumn{3}{|c|}{ Consume enough protein } \\
\hline Yes & 262 & 83.4 \\
\hline No & 52 & 16.6 \\
\hline \multicolumn{3}{|l|}{ Skip meals } \\
\hline Yes & 292 & 93 \\
\hline No & 22 & 7 \\
\hline \multicolumn{3}{|c|}{ Do you drink tea or coffee? } \\
\hline Yes & 201 & 64 \\
\hline No & 113 & 36 \\
\hline \multicolumn{3}{|l|}{ How many cups of tea } \\
\hline 4 cups/day & 78 & 25 \\
\hline 3 cups/day & 60 & 19 \\
\hline 2 cups/day & 85 & 27 \\
\hline $1 \mathrm{cup} /$ day & 91 & 29 \\
\hline \multicolumn{3}{|c|}{ How many cups of coffee } \\
\hline 4 cups/day & 66 & 21 \\
\hline 3 cups/day & 79 & 25 \\
\hline 2 cups/day & 100 & 32 \\
\hline $1 \mathrm{cup} / \mathrm{day}$ & 69 & 22 \\
\hline \multicolumn{3}{|c|}{ Did you get iron prescription during your pregnancy? } \\
\hline Yes & 302 & 97.18 \\
\hline No & 12 & 3.8 \\
\hline \multicolumn{3}{|c|}{ For how long you took the iron prescription } \\
\hline Less than a month & & 6.6 \\
\hline 1 to 2 months & 45 & 14.3 \\
\hline More than 2 months & 248 & 78.89 \\
\hline \multicolumn{3}{|c|}{ Hemoglobin level in current pregnancy } \\
\hline Low & 1 & 0.3 \\
\hline Normal & 313 & 99.7 \\
\hline
\end{tabular}

\subsection{Study participant's knowledge regarding iron deficiency anemia}

Table 4 illustrates participant's knowledge regarding anemia during pregnancy. It is clear that almost all the women participated in this study reported yes regarding all the items on the knowledge of anemia scale as follow: anemia is a deficiency of red blood cells, hemoglobin less than $11 \mathrm{~g} / \mathrm{dL}$ is considered anemia, hemoglobin level during pregnancy should be higher, infections can cause anemia, insufficient iron rich food during pregnancy can cause anemia, periods between pregnancies may prevent anemia, pale face and tongue are common signs of anemia, feeling tired and easy fatigue are signs of anemia, anemia is life threatening during pregnancy, anemia may cause low birth weight baby, liver and red meat are rich in iron, tea and coffee during eating may reduce iron absorption, pregnant women who have anemia should take iron daily, hospitals and mother health centers provide iron for pregnant women. Regarding the item "drinking citrus juices during eating would help iron absorption" $92.3 \%$ reported no and $7.7 \%$ reported yes. 
Table 4: Study Participant's Knowledge of Iron Deficiency Anemia during Pregnancy

\begin{tabular}{|c|c|c|c|c|c|c|}
\hline \multirow{2}{*}{ Items } & \multicolumn{2}{|c|}{ Yes (2) } & \multicolumn{2}{|c|}{ No (1) } & \multicolumn{2}{|c|}{ Don't' know (0) } \\
\hline & $\mathrm{n}$ & $\%$ & $\mathrm{n}$ & $\%$ & $\mathrm{n}$ & $\%$ \\
\hline Anemia is a deficiency of red blood cells & 314 & 100 & 0 & 0 & 0 & 0 \\
\hline Hemoglobin less than $11 \mathrm{~g} / \mathrm{dL}$ is considered anemia & 313 & 99.7 & 0 & 0 & 1 & .3 \\
\hline Hemoglobin level during pregnancy should be higher, & 314 & 100 & 0 & 0 & 0 & 0 \\
\hline Infections can cause anemia & 314 & 100 & 0 & 0 & 0 & 0 \\
\hline Insufficient iron rich food during pregnancy can cause anemia & 314 & 100 & 0 & 0 & 0 & 0 \\
\hline Periods between pregnancies may prevent anemia & 314 & 100 & 0 & 0 & 0 & 0 \\
\hline Pale face and tongue are common signs of anemia & 314 & 100 & 0 & 0 & 0 & 0 \\
\hline Feeling tired and easy fatigue are signs of anemia & 314 & 100 & 0 & 0 & 0 & 0 \\
\hline Anemia is life threatening during pregnancy & 314 & 100 & 0 & 0 & 0 & 0 \\
\hline Anemia may cause low birth weight baby & 314 & 100 & 0 & 0 & 0 & 0 \\
\hline Liver is rich in iron & 311 & 99 & 0 & 0 & 3 & 1 \\
\hline Red meat is rich in iron & 311 & 99 & 0 & 0 & 3 & 1 \\
\hline Tea and coffee during eating may reduce iron absorption & 308 & 98 & 6 & 2 & 0 & 0 \\
\hline Pregnant women who have anemia should take iron daily & 311 & 99 & 3 & 1 & 0 & 0 \\
\hline Hospitals and mother health centers provide iron for pregnant women. & 311 & 99 & 0 & 0 & 3 & 1 \\
\hline Citrus juice during eating would help iron absorption & 24 & 7.7 & 287 & 92.3 & 0 & 0 \\
\hline
\end{tabular}

As shown in figure 1, total level of knowledge was calculated to better present level of knowledge. Results showed that $94 \%$ reported good level of knowledge, $4.5 \%$ fair level of knowledge and $0.5 \%$ poor level of knowledge regarding anemia during pregnancy.

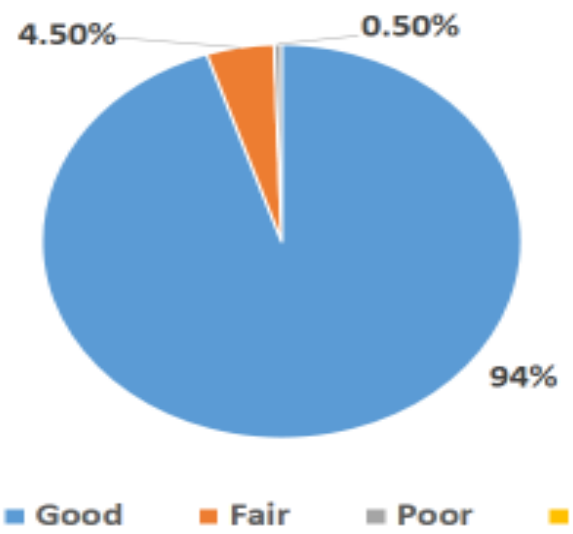

Fig. 1: Participant's Level of Knowledge about Iron Deficiency Anemia during Pregnancy.

\subsection{Pregnant women attitude regarding iron deficiency anemia}

As shown in Table 5, women attitude toward anemia during pregnancy portrayed that majority (97\% to 99.7\%) agreed to all the items of the practice scale. For instance, they agreed that they are at risk for developing anemia during pregnancy, if they are anemic, they would take iron, if they are anemic they would take vitamins and eat well, agreed that they would not eat what they want if the doctor described different food for them, agreed that they use special nutritional habits during pregnancy, agreed that checkup and following special diet routine are important during pregnancy, the mother and the baby get benefits from iron, and use of family planning methods are important to avoid anemia. Results showed that $99 \%$ of participants have positive attitude and $1 \%$ have negative attitude toward anemia during pregnancy.

Table 5: Participant's Attitude toward Iron Deficiency Anemia during Pregnancy

\begin{tabular}{|c|c|c|c|}
\hline Items & $\begin{array}{l}\text { Agree } \\
(3)\end{array}$ & $\begin{array}{l}\text { Neutral } \\
(2)\end{array}$ & $\begin{array}{l}\text { Do not agree } \\
\text { (1) }\end{array}$ \\
\hline Are you at risk for anemia during pregnancy & $97.7 \%$ & 0 & $2.3 \%$ \\
\hline If I am anemic, I would take iron supplement & $99.7 \%$ & 0 & 0.3 \\
\hline If I am anemic, I would take vitamins and eat well & $99.7 \%$ & 0 & $0.3 \%$ \\
\hline I wouldn't eat what I want if the doctor described different food & $99.4 \%$ & 0 & $0.6 \%$ \\
\hline I use special nutritional habits during pregnancy & $97 \%$ & 0 & $3 \%$ \\
\hline Checkup and following special diet during pregnancy are important & $99.7 \%$ & 0 & $0.3 \%$ \\
\hline The mother \& the Baby get benefits from iron \& good nutrition during pregnancy & $99.7 \%$ & 0 & $0.3 \%$ \\
\hline Total Attitude & $\begin{array}{l}\text { Positive } \\
99 \%\end{array}$ & $\begin{array}{l}\text { Neutral } \\
0 \%\end{array}$ & $\begin{array}{l}\text { Negative } \\
1 \%\end{array}$ \\
\hline
\end{tabular}

\subsection{Is there a relationship between selected demographic and obstetric variables and women knowledge, attitude and practice toward anemia during pregnancy?}

To explore if there is a relationship between demographic characteristics of the women (age, education, work, income), their obstetric variables (gravidness, parity, medical history, surgical history, obstetric surgery) and women's knowledge and attitude regarding anemia during pregnancy, Pearson correlation (Table 6) revealed that there was statistical significance association between education and knowledge $\left(\mathrm{r}=.39^{* *}, \mathrm{p}=.003\right)$ meaning that the women who were well educated reported good level of knowledge about anemia during pregnancy. In addition, education reported significance association with attitude $(\mathrm{r}=.29 * *, \mathrm{p}=.003)$, women who were well educated reported positive attitude toward anemia during pregnancy. . Further, education reported significance association with practice regard- 
ing anemia during pregnancy $(\mathrm{r}=.33 * *, \mathrm{p}=.02)$ indicating that women who were well educated had good practice to avoid anemia during pregnancy. Income also showed significance association with practice $\left(r=.31^{* *}, p=.002\right)$ which mean that women who have good monthly income were more likely to show good practice to avoid anemia during pregnancy. The other demographic variables such as age, work and income did not show association with knowledge and attitude. Further, obstetric variables such as parity, gravidness, complication during previous pregnancy, medical history, surgical history and obstetric history did not show association with knowledge and attitude.

\subsection{Risk factor analysis}

Questions in the Knowledge, Attitude, and Practice section were scored appropriately and comparison was done with reported Hb levels. Correlation coefficient was applied in order to identify any possible relation between the variables.

Table 6: Correlation Among Demographic Variables, Obstetric Variables and Women's Knowledge, and Attitude Regarding Anemia during Pregnancy

\begin{tabular}{llll}
\hline Demographic and Obstetric Variables & Knowledge & Attitude & Practice \\
\hline \multirow{2}{*}{ Age } & $\mathrm{r}=.018$ & $\mathrm{r}=.008$ & $\mathrm{r}=.01$ \\
& $\mathrm{p}=.93$ & $\mathrm{p}=.45$ & $\mathrm{p}=.31$ \\
Education & $\mathrm{r}=.39^{* *}$ & $\mathrm{r}=.29^{* *}$ & $\mathrm{r}=.33^{* *}$ \\
Work & $\mathrm{p}=.003$ & $\mathrm{p}=.03$ & $\mathrm{p}=.02$ \\
& $\mathrm{r}=.001$ & $\mathrm{r}=.021$ & $\mathrm{p}=.29$ \\
Income & $\mathrm{p}=.53$ & $\mathrm{p}=.34$ & $\mathrm{r}=.31^{* *}$ \\
& $\mathrm{r}=.006$ & $\mathrm{p}=.002$ & $\mathrm{r}=.001$ \\
Gravidness & $\mathrm{p}=.35$ & $\mathrm{p}=.45$ & $\mathrm{p}=.43$ \\
Parity & $\mathrm{r}=.03$ & $\mathrm{r}=.005$ & $\mathrm{r}=.001$ \\
& $\mathrm{p}=.51$ & $\mathrm{p}=.73$ & $\mathrm{p}=.71$ \\
Complications & $\mathrm{r}=.008$ & $\mathrm{r}=.021$ & $\mathrm{p}=.032$ \\
& $\mathrm{p}=.72$ & $\mathrm{p}=.81$ & $\mathrm{r}=.82$ \\
Medical history & $\mathrm{r}=.031$ & $\mathrm{r}=.10$ & $\mathrm{p}=.011$ \\
Surgical history & $\mathrm{p}=.39$ & $\mathrm{p}=.81$ & $\mathrm{r}=.03$ \\
& $\mathrm{r}=.09$ & $\mathrm{r}=.001$ & $\mathrm{p}=.29$ \\
Obstetric surgery & $\mathrm{p}=.35$ & $\mathrm{p}=.51$ & $\mathrm{r}=.023$ \\
NB. r means correlation; bold numbers show significant findings. & $\mathrm{r}=.005$ & $\mathrm{p}=.09$ & $\mathrm{p}=.43$ \\
\hline
\end{tabular}

Table 7: Correlation Analysis between Knowledge Score and HB Level (N=314)

\begin{tabular}{lllcl}
\hline Variable & Mean & SD & Correlation & P value \\
\hline $\begin{array}{l}\text { Knowledge } \\
\text { Score }\end{array}$ & 22.01 & 4.93 & .082 & .273 \\
$\mathrm{Hb}$ g/dl & 10.14 & 1.76 & & \\
\hline
\end{tabular}

Table 8: Correlation Analysis between Attitude Score and HB Level ( $\mathrm{N}=314)$

\begin{tabular}{lllll}
\hline Variable & Mean & SD & Correlation & P value \\
\hline Attitude & 13.16 & 1.80 & -.004 & .960 \\
Score & 10.14 & 1.76 & & \\
$\mathrm{Hb}$ g/dl & & & & \\
\hline
\end{tabular}

Table 9: Correlation Analysis between Practice Score and HB Level (N=314)

\begin{tabular}{lllll} 
& \multicolumn{1}{c}{ Table 9: Correlation Analysis between Practice Score and HB Level $(\mathrm{N}=314)$} & P value \\
\hline Variable & Mean & SD & Correlation & 0.022 \\
\hline $\begin{array}{l}\text { Practice } \\
\text { Score }\end{array}$ & 6.18 & 2.00 & .143 & \\
$\mathrm{Hb}$ g/dl & & 1.76 & & \\
\hline
\end{tabular}

\section{Discussion}

The current study showed good level of knowledge and positive attitude regarding anemia during pregnancy. Many reasons could have been contributed to this result. First, majority of the women in this study were relatively young since $42 \%$ were in the age group 21 to 30 years old. Being young, recently graduates with few responsibilities would have contributed to having enough time to enjoy being pregnancy and gather information about how to take care of health during pregnancy. Second, $49 \%$ were university graduates, well-educated people tend to acquire information and expand their awareness regarding many aspects of their life including health. Third, majority of the women participated in this study were housewives who have monthly income of more than 5,000 Saudi Riyals. Housewives have enough time to adhere to antenatal follow up, choose healthy food, and have no work-related stress.

Our results were congruent with Mohannad et al. (2012) who reported a good level of awareness regarding anemia among women in their study. Kalimbira et al. (2009) in their study about maternal knowledge and practices related to anemia and iron supplementation reported that majority of the women answered correctly questions related to definition of anemia, causes, signs, prevention, and treatment. In the same study majority showed that eating adequate amounts of food is a means of preventing anemia. Earlier studies show that $57 \%$ of the pregnant women who are attending antenatal clinics reported good knowledge regarding prevention of anemia during pregnancy. Although, they concluded that women reported poor practice regarding anemia prevention during pregnancy, but factors such as education, living in urban areas, nuclear family type, previous history of anemia and good practice were significantly associated with knowledge. Adznam et al. (2018) assessed knowledge, attitude and practice of pregnant women in Malaysia. They reported a high mean of knowledge scores regarding anemia. 
On the other hand, our results were not in accordance with many previous works, Nivedita \& Shanthini (2016) showed that only $39 \%$ of the women participated in their study showed good knowledge regarding the term anemia and generally women reported low level of knowledge. Yadav et al. (2014) also reported lack of knowledge regarding iron deficiency anemia among women in their study. Ahmed et al. (2018) showed that $60 \%$ of the women in their study reported poor knowledge regarding anemia during pregnancy. Ghimire \& Pandey (2013) reported that more than 50\% of the women participated in their study had unsatisfactory knowledge about anemia. Some studies reported also lack of awareness among women regarding anemia during pregnancy.

Regarding nutritional practice, our results also showed that $64 \%$ of the women participated in the study used to drink tea/ coffee. Out of those, $44 \%$ were drinking 3 to 4 cups of tea daily, and $46 \%$ were drinking 3 to 4 cups of coffee daily. Previous research showed that there is no association between drinking tea and coffee and anemia (Munoz, et al. 1988, Kumera et al. 2018). Drinking coffee and tea might affect iron absorption due to its effect as an inhibitor of absorption which cause anemia. This can be a major issue during pregnancy especially if the dietary intake of iron is not enough (WHO, 2011). The current study did not assess the time of drinking tea/coffee, but majority of women showed that drinking tea and coffee during eating may reduce iron absorption, majority reported taking Iron for more than 2 months during their pregnancy, and majority showed good level of knowledge regarding anemia during pregnancy. These factors would contributed to women practice and in turn no anemia was reported among women ion this study. So, strong positive linear correlation between the two variables was found with statistically highly significant association.

Majority (93\%) of the women in this study reported that they skip meals sometimes. The reasons behind skipping meals were not investigated in this study, but women had good nutritional practice and knowledge regarding anemia. This might improve their concern regarding their health and encouraged them to practice good dietary intake which was supported in this study and others (Mirsanjaril et al. 2012, Painter 2003, Alemayehu \& Tesema 2014).

Our results showed that among demographic and obstetric variables, only education reported significance association with knowledge. This was similar to Kalimbira et al. (2009) who showed that educated women reported better knowledge compared to illiterate.

Although, one quarter of study sample were illiterate, $25 \%$ had secondary school education and $12 \%$ reported having a master's degree, the study of Abdelhafez and El-Soadaa (2011) reported association between education and level of knowledge of iron-rich food. Mirsanjaril et al. (2012) also reported association between education and knowledge regarding anemia during pregnancy.

Regarding pregnant women attitude toward anemia during pregnancy, 99\% in our study showed positive attitude. This was in agreement with Ahmed et al. (2018) who reported that $80 \%$ of the studied women had positive attitude toward anemia. Adznam et al. (2018) showed positive attitude among women in their study. Their study concluded that positive attitude regarding anemia influenced the good level of knowledge and good practices among women.

Our results were in disagreement with M'Cormack \& Drolet (2012) and Margwe (2015) who found that there is unfavorable attitude toward anemia among women in their studies. Whereas an inverse relation exists among attitude of respondents and their Hb levels with a non-significant; indicates towards strongly negative correlation among these two variables. This finding is in contrast to previous finding where highly significant positive correlation was found among attitude score and respondent's Hb levels.

Education on the other side reported significance association with attitude in our study which supported by Daba et al. (2013), Adznam et al. (2018) who concluded that there were strong association between education and attitude.

\subsection{Limitations}

Although the current study showed that women have good knowledge and positive attitude toward anemia during pregnancy, the study did not look at women's practice. Knowledge and attitude would drive the practice and would uncover more information about this phenomenon. The study used cross sectional design for only anti natal period, including a post natal follow up to measure the pregnancy outcomes would have provided wider understanding.

\section{Conclusion}

The present study showed an evidence of good level of knowledge and positive attitude about anemia during pregnancy. Saudi women are aware of what is anemia, causes, signs and symptoms, food rich in iron and the importance of iron supplement. They also reported good knowledge regarding interval between children to avoid anemia. The reported good level of knowledge could have been contributed to women's positive attitude toward anemia during pregnancy. Previous research supports the idea that knowledge and awareness drive attitude and practice. Although, the current study did not assess women's practice regarding anemia, but women's good knowledge and positive attitude would have been indirectly affected their practice. In addition, results also showed that majority of the women participated in the study reported having no anemia. This indicates that Saudi women are aware of good health habits and they have the ability to practice healthy behaviors. Appropriate nutritional counseling during antenatal follow up should be encouraged and should include women in reproductive age. Awareness should be also extended to included adolescent girls to have a safe pregnancy and maternal outcomes.

\subsection{Recommendations}

- $\quad$ Repeating the study with larger sample and multi-sites would provide a more representative population.

- Anti-natal care providers should focus on the importance of preventing Iron deficiency anemia and early referral of cases who are at risk.

- Increase women awareness regarding the importance of not skipping any meals and avoiding drinking tea and coffee during pregnancy to avoid getting anemia. This could be achieve through mass media and during anti natal care follow up.

- Enhance the good level of knowledge and the positive attitude generally among Saudi women and specifically during pregnancy through continuous awareness campaigns and booklets provided by health care providers to women during follow up.

- Saudi women in the current study reported good results in terms of good knowledge, attitude and nutritional practice during pregnancy. This should be encouraged and enhanced among all women through media. 


\section{References}

[1] Foote EM, Sullivan KM, Ruth LJ, Oremo J, Sadumah I, Williams TN \& Suchdev PS (2013) Determinants of anemia among preschool children in rural, western Kenya. The American Journal of Tropical Medicine and Hygiene, 88, 757-764. https://doi.org/10.4269/ajtmh.12-0560.

[2] Estadella J, Villamarín L, Feliu A, Perelló J \& Calaf J (2018) Characterization of the population with severe iron deficiency anemia at risk of requiring intravenous iron supplementation. European Journal of Obstetrics \& Gynecology and Reproductive Biology, 224 , 41-44. https://doi.org/10.1016/j.ejogrb.2018.03.005

[3] Lokeshwar MR, Mehta M, Mehta N, Shelke P \& Babar N (2011) Prevention of iron deficiency anemia (IDA): how far have we reached? The Indian Journal of Pediatrics, 78, 593-602. https://doi.org/10.1007/s12098-010-0130-1.

[4] Nivedita K \& Shanthini F (2016) Knowledge, attitude and practices of pregnant women regarding anemia, iron rich diet and iron supplements and its impact on their hemoglobin levels. International Journal of Reproduction, Contraception, Obstetrics and Gynecology, 5, 425-431. https://doi.org/10.18203/2320-1770.ijrcog20160383.

[5] World Health Organziation. The global prevalence of anemia in 2011. Available at: http://www.who.int/ nutrition/ publications/ micronutrients/ global_prevalence_anaemia_2011/e n/. Accessed January 9, 2019.

[6] Horwath CC (1999) Applying the Trans Theoretical Model to eating behavior change: challenges and opportunities. Nutrition Research Review. 12, 281-317. https://doi.org/10.1079/095442299108728965.

[7] Fox C \& Kilvert A (2003) Intensive education for lifestyle change in diabetes. British Medical Journal, 327, 1120-1121. https://doi.org/10.1136/bmi.327.7424.1120.

[8] Macias YF \& Glasauer P (2014) Guidelines for assessing nutrition related knowledge, attitude, and practices. Food and Agriculture Organization of United Nations. Available at: http://www.fao.org/docrep/019/13545e/13545e.pdf. Accessed January 9, 2019.

[9] Mohannad A, Rizvi F \& Irfan G (2012) Impact of maternal education, and socioeconomic status on maternal nutritional knowledge and practices regarding iron rich foods and iron supplements, Annals of Pakistani Institute of Medical Science, 8, 101-105.

[10] Kalimbira AA, Mtimuni BM \& Chilima DM (2012) maternal knowledge and practices related to anaemia and iron supplementation. African Journal of Food Agriculture and Nutritional Development, 550-564.

[11] Adznam SH, Sedek R \& Kasim ZM (2018) Assessment of knowledge, attitude and practice levels regarding anaemia among pregnant women in Putrajaya, Malaysia. Pakistan Journal of Nutrition, 17, 578-585. https://doi.org/10.3923/pjn.2018.578.585.

[12] Yadav RK, Swamy MK \& Banjade B (2014) Knowledge and practice of anemia among pregnant women attending antenatal clinic in Dr. Prabhakar Kore Hospital, Karnataka-A cross sectional study. IOSR Journal of Dental and Medical Sciences, 13, 74-80. https://doi.org/10.9790/085313477480.

[13] Ahmed N, Kotob S \& Hassanen R (2018) Knowledge and attitude of pregnant women about iron deficiency anemia in Assist University Women Health Hospital, Egypt. Journal of Nursing and Health Science, 7, 49-58.

[14] Ghimire N \& Pandey N (2013) Knowledge and practice of mothers regarding the prevention of anemia during pregnancy, in teaching hospital, Kathmandu. Journal of Chitwan Medical College, 3, 14-17. https://doi.org/10.3126/jcmc.v3i3.8631.

[15] Munoz L, Lönnerdal B, Keen CL, \& Dewey KG (1988). Coffee consumption as a factor in iron deficiency anemia among pregnant women and their infants in Costa Rica. The American Journal of Clinical Nutrition, 48, 645-651. https://doi.org/10.1093/ajcn/48.3.645

[16] Kumera G, Haile K, Abebem N \& Eshete T (2018) Anemia and its association with coffee consumption and hookworm infection among pregnant women attending antenatal care at Debre Markos Referral Hospital, Northwest Ethiopia. PLoS One, 13, e0206880. https://doi.org/10.1371/journal.pone.0206880.

[17] Alemayehu MS \& Tesema EM (2015) Dietary practice and associated factors among pregnant women in Gondar town northwest, Ethiopia, 2014. International Journal of Nutrition \& Food Science, 4, 707-712. https://doi.org/10.11648/j.ijnfs.20150406.27.

[18] Mirsanjaril M, Muda D, Ahmad A \& Othman MS. Does nutritional knowledge have relationship with healthy dietary attitude and practices during pregnancy? International conference on nutrition and food sciences. IPCBEE 2012, vol. 39. Singapore: IACSIT Press.

[19] Painter J, Rah J \& Lee Y (2003) Comparison of international food guide pictorial representation. Journal of American Diet Association, 102, 483489. https://doi.org/10.1016/S0002-8223(02)90113-6.

[20] Abdelhafez AM \& El-Soadaa SS. Prevalence and risk factors of anemia among a sample of pregnant. Pakistan Journal of Nutrition, 11, 1113-1120. https://doi.org/10.3923/pjn.2012.1113.1120.

[21] M'Cormack F \& Drolet J (2012) Assessment of anemia knowledge, attitudes and behaviors among pregnant women in Sierra Leone. The Health Educator, 44, 9-14.

[22] Margwe J. (2015) Prevalence, knowledge and attitude of pregnant women on control measures od anemia in Mbuludistric,Tanzania. Master Thesis of Science in Public Health and Food Safety Sokoine University of Agriculture, Morogoro, Tanzania.

[23] Daba GF, Beyene H, Fekadu W \& Garoma W (2013) Assessment of knowledge of pregnant mothers on maternal nutrition and associated factors in Guto Gida Woreda, East Wollega Zone, Ethiopia Journal of Nutrition and Food Sciences, 3, 213-219. https://doi.org/10.4314/star.v2i3.98748. 